\title{
CURRENT STATUS OF INFERTILITY COUNSELING IN KOREA
}

Ra Hyun Kim, MD', Won Moo Lee, MD', Young Jae Kim, MD, PhD', Young Mo Sung, MD'1, Jeong Kyu Hoh, MD, PhD', Dong woon Han, MD, PhD², Young Min Choi, MD, PhD³ , Jung Hye Hwang, MD, PhD ${ }^{1}$

Departments of ${ }^{1}$ Obstetrics and Gynecology, ${ }^{2}$ Preventive Medicine, Hanyang University College of Medicine, Seoul; ${ }^{3}$ Department of Obstetrics and Gynecology, Seoul National University College of Medicine, Seoul, Korea

\section{Objective}

The recent fertility decline deepened concern about the emotional side of infertility problems as well as social, ethical, legal and psychological aspect and increased awareness of the importance of consultation. In this study, we evaluated the current condition of infertility counseling for couples participated in the project supporting infertile couples by Ministry of Health and Welfare in Korea.

\section{Methods}

Postal survey was administered to infertility couples who received medical cost support in 2006 and 2008. We investigated 11 different of infertility counseling through the postal survey.

\section{Results}

The most common number was two or three sessions of counseling before infertility treatment (409 cases in 2006, 534 cases in 2008 , respectively). The most common counselor to infertile couples was a physician, $(1,009$ cases in 2006,879 cases in 2008 , respectively). The most common form of counseling was verbal counseling in the office of the physician to the patient or couple alone and psychological testing was not performed in 1,133 cases among 1,182 cases in 2006 and 1,105 among 1,227 in 2008 respectively. One of the most stressful events during treatment was results announcement and the most helpful person was the spouse.

\section{Conclusion}

Many infertile couples who received the psychological counseling answered that it was helpful in stabilizing the emotional status of patients and professional psychological counseling of infertile couples with access as a teams will be needed. Further investigations are needed to study the effects that various infertility counseling methods can promote the infertility treatment process and outcomes.

Keywords: Infertility; Infertility counseling; In vitro fertilization-embryo transfer

불임이란 피임을 하지 않은 상태로 1년간 부부생활을 한 후에도 임신 이 되지 않는 경우를 말한다. 결혼 후 피임을 하지 않는 경우 첫 1년내 $80 \%$ 가 임신을 하는 것으로 보고되어 있으며 결혼한 부부의 8-14\%가 불임을 경험하는 것으로 추정되고 있다. 최근 체외수정을 포함한 보조 생식술을 이용한 의학적 불임 치료에 대한 수요의 증가와 불임에 대한 대중의 관심의 증가, 그리고 체외수정 및 배아이식술(in vitro fertilizationembryo transfer, IVF-ET; 시험관 아기), 접합자 난관내이식, 난자세포질 내정자주입술, 보조부회술 등 많은 최신 기법들이 불임 치료를 위하여 개발되었으며, 난자 공여, 정자 공여, 대리모 등 제삼자 생식 방법을 사 용하여 임신을 시도하는 경우도 증가되고 있다. 이러한 보조생식술 관 련한 의학기술이 발전함에 따라 동시에 사회적, 윤리적, 법적인 문제뿐 만 아니라 불임 환자의 심리적, 정신적인 면에 대한 관심도 증가되면서 불임상담의 중요성에 대한 인식도 증가되고 있다.
Received: 2011. 5.31. Revised: 2011. 7.15. Accepted: 2011. 8. 4. Corresponding author: Jung Hye Hwang, MD, PhD Department of Obstetrics and Gynecology, Hanyang University College of Medicine, 17 Haengdang-dong, Seongdong-gu, Seoul 133-791, Korea Tel: +82-2-2290-8408 Fax: +82-2-2296-8472 E-mail: hwangjh@hanyang.ac.kr

This is an Open Access article distributed under the terms of the Creative Commons Attribution Non-Commercial License (http://creativecommons.org/licenses/ by-nc/3.0/) which permits unrestricted non-commercial use, distribution, and reproduction in any medium, provided the original work is properly cited.

Copyright (๑ 2011. Korean Society of Obstetrics and Gynecology 


\title{
KOREAN JOURNAL OF OBSTETRICS \& GYNECOLOGY
}

\author{
KJOG Vol. 54, No. 10, 2011
}

불임상담 분야는 불임을 포함한 생식의학 문제를 가지고 있는 환자 들을 상담하고 도와주는 것이 목적으로 심리학과 생식의학영역이 포함 되는 전문분야이다. 이는 생식의학에 대한 공통적인 관심과 목적을 공 유하는 정신건강전문가 그룹에 의해서 이루어지는데, 크게 의학적인 면을 담당하는 분야 즉 불임 환자를 상담하고, 의학적인 치료를 제공하 는 의료인으로 의사, 간호사, 실험실 전문가 등과 심리학 분야를 담당 하는 심리학자, 정신과의사, 사회사업가 등이 포함된다[1]. 의료전문가 의 일차적인 관심은 불임의 진단과 치료이지만, 불임상담가의 일차적 인 관심은 환자 개개인 및 부부의 의학적인 상태와 불임 장애의 범위 내에서 이루어지는 심리적 배려와 치료이다. 최근 정신건강전문가의 중요성이 생식의학 분야에서 점점 커지고 있는 이유는 생식의학의 기 술적 발달과 이와 관련한 불임부부의 복잡한 심리사회적 문제와 요구 때문이다[2].

우리나라는 연간 체외수정 및 배아이식술을 포함한 불임시술을 약 2 만 건 이상 시행하고 있는 국가로 미국이나 유럽국가들에 비하여 임신 율 역시 높은 수준을 유지하고 있다[3]. 외국의 경우 보조생식술 이전에 불임상담을 충분히 하도록 되어 있으며, 이미 불임상담 가이드라인이 제시되어 있는 국가도 있다[4]. 그러나 우리나라에서는 불임상담에 대한 관심은 아직 낮고, 상담 실태에 대해서도 거의 알려진 바가 없는 실정이 다. 이에 본 연구에서는 우리나라에서의 불임상담 실태를 불임부부 지 원사업을 받은 환자들을 대상으로 2006년과 2년 후인 2008년 2차례에 걸쳐 조사한 내용을 분석하였다.

\section{연구대상 및 방법}

본 연구는 2006년과 2008년, 2회에 걸쳐 불임부부 지원사업의 시 술비를 지원받은 불임환자를 대상으로 하였다. 불임부부 지원사업은 2006년 1월 1일부터 보건복지부가 주관하고 있는 국가적인 사업으로

Table 1. Medical Indication for national supporting programs for infertility couples

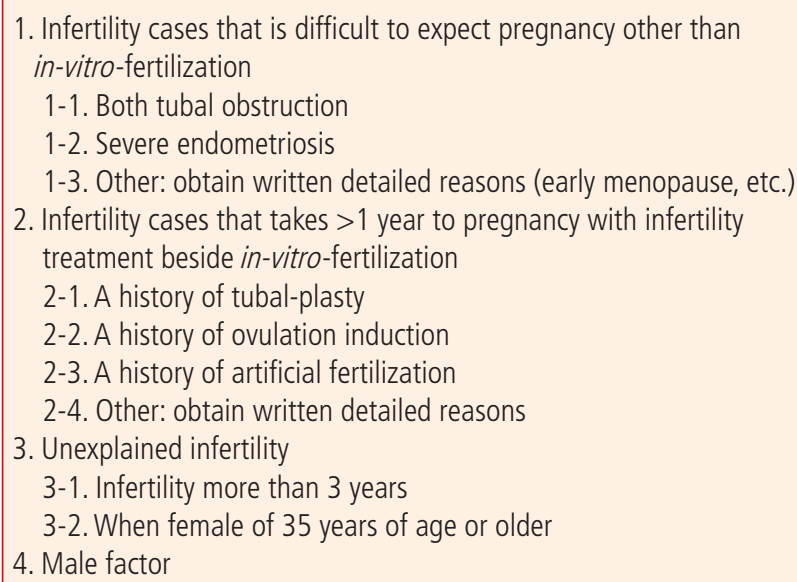

근본 목적은 저출산 문제 해결을 위한 것이다. 이는 불임 부부에게 일정 소득 요건이 되면 체외수정 및 배아이식술을 포함한 보조생식술과 관련 한 비용을 정부에서 평생 3회까지 지원해 주는 것으로 체외수정 및 배 아이식술의 의학적 지원 기준은 Table 1 에 요약되어 있다.

자료 수집은 불임부부지원 사업의 수혜를 받은 환자들을 대상으로, 즉 2006년 19,131예 중 7,931예와 2008년 13,240예(총 21,171예) 대 상으로 우편설문조사를 실시하였다. 설문 내용은 불임상담과 관련하여 상담횟수, 상담자, 비용, 상담 형태, 상담 장소, 상담 방법, 심리검사유무, 스트레스를 받은 시술종류, 시술 시 가장 도움을 준 사람, 그리고 병원 을 옮긴 적이 있는 지 등 10 개의 영역에서 시행되었다.

자료 분석 및 통계처리는 SPSS ver. 15.0 (SPSS Inc., Chicago, IL, USA)를 활용하여 분석하였고 측정치의 기술통계량은 빈도 및 백분율로 표시하였다. 복수응답자료에 대하여는 다중응답처리를 하였다.

\section{결 과}

\section{1. 연구대상의 일반적 특성}

전체 설문 대상자는 21,171 명이였다. 이중 설문 회신은 총 2,581예로 회신율은 각각 2006년 7,931명 중 1,250명(15.8\%), 2008년 13,240명 중 1,331 명 $(10.1 \%)$ 으로 평균 회신율은 $12.2 \%$ 였다.

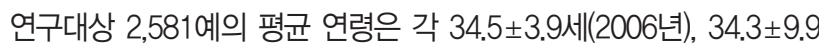
세(2008년)였으며, 연령 분포는 30-34세 사이가 2006년, 2008년 모두 가장 많았고, 35-39세 사이가 두 번째로 많아 대부분이 30-39세 사이 였다FIg. 1). 평균 불임기간은 $71.0 \pm 38$.8개월(2006년), $57.4 \pm 12.7$ 개월 (2008년)로 2006년의 경우 4년-6년 사이가 가장 많았으나 2008년에 는 2년에서 4년 사이가 많았다(Fig. 2).

\section{2. 결과}

\section{1) 불임시술 이전에 상담 받은 횟수}

불임부부들이 시험관아기 시술 전에 상담을 받은 횟수를 보면 2내지 3 회 상담 받았다'는 경우가 가장 많았는데, 각 2006년 409명(33.4\%), 2008년 534명(42.4\%)이었다. 반면 '전혀 상담을 받지 않았다'는 응답 이 2006년의 경우 113 명(9.3\%)이었고 2008년의 경우 308명(24.4\%) 로 2008년에 상담을 받지 않은 경우가 유의하게 많았다 $(P<0.05)$. 그외 또한 2008년에는 4회 이상 상담한 경우가 2006년에 비해 유의하게 낮 게 나타났는데 각 310 명(25.3\%, 2006년), 17명(1.4\%, 2008년)이었다 $(P<0.05)$. 기타 응답으로는 '기회가 있는 대로 하였다'와 '갈 때마다 받 았다', '5회 이상 받았다' 등이 있었다(Fig. 3).

\section{2) 불임상담자}

불임부부에게 불임상담을 해준 상담자로 불임전문의에게 상담을 받 았다고 한 경우가 가장 많았는데, 2006년은 1,009명(85.5\%), 2008년 은 879 명 $(67.7 \%)$ 이었으며, 불임 전문 간호사에게 상담을 받았다는 경우 가 2번째로 많았는데 2006년 111명(9.4\%), 2008년 202명(15.6\%)이었 


\section{KOREAN JOURNAL OF OBSTETRICS \& GYNECOLOGY}

Ra Hyun Kim, et al. Infertility counseling in Korea

다. 2006년에 비해 2008년에는 전문의에게 상담을 받은 경우는 감소하 고, 간호사에게 상담을 받은 경우는 증가한 양상을 보였다. 정신과 의사 나 심리학자로부터 상담을 받았다는 경우는 2006년 17명(1.4\%), 2008 년 26명(2.0\%)로 2006년에 비해 약간 증가한 양상을 보였으나 외국에 비하여 낮은 비율을 보였다. 그 외 일반산부인과 의사나 한의사 등이 상 담해 주었다는 경우도 있었다(Table 2).

\section{3) 불임상담 비용}

불임상담 후 상담비용을 ‘따로 지불하지 않았다'가 가장 많았는데, 2006년은 1,121명 중 659명(58.8\%), 2008년은 1,250명 중 765명 (61.3\%)이었다. 그리고 2만원 이하의 비용을 지불한 경우가 두번째로 많았다. 기타 '기억이 나지 않는다' 또는 '진료비에 포함되었는지 모른 다' 등의 응답이 있었다(Table 3).
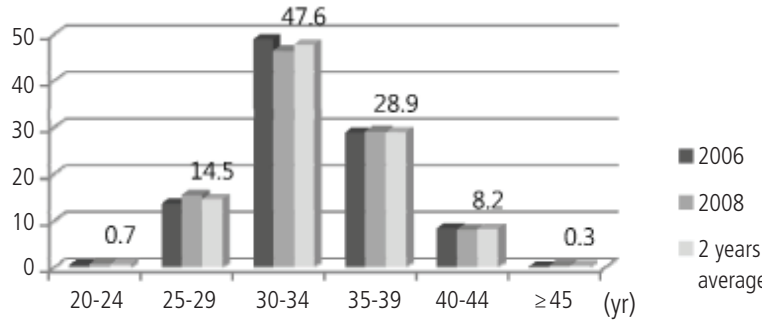

Fig. 1. Distribution of age of entire participants.

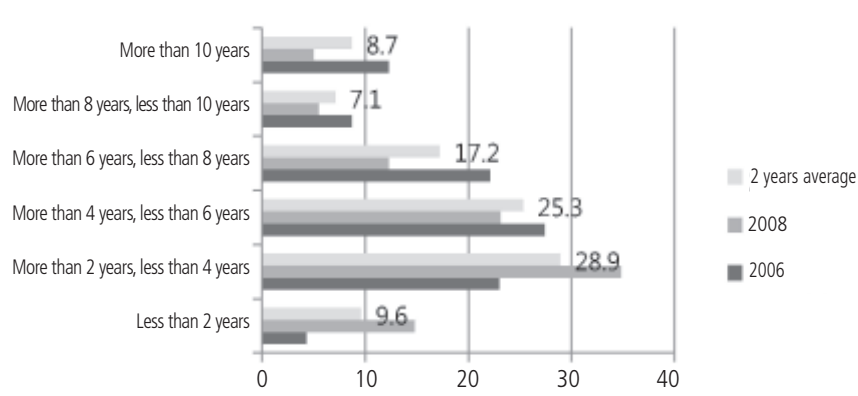

Fig. 2. Duration of infertility.

\section{4) 불임상담 방법}

(1) 불임상담 형태

불임상담의 형태를 보면 불임환자나 부부 단독으로 상담 받은 경우가 대부분으로 2006년은 1,173명 중 1,134명(96.7\%), 2008년은 1,262명 중 1060명(84\%)였다. 그외 2-5명씩 소그룹으로 받은 경우, 5명 이상 상담을 받은 경우의 순서였다. 그리고 '불임부부가 상담을 함께 받은 경 우가 $50.4 \%$ 였고 환자 혼자 상담을 받은 경우는 $48.3 \%$ 였다(Table 4).

\section{(2) 불임상담 방법}

불임상담 방법으로 그림을 그리면서 설명한 구두설명이 가장 많았는 데, 각 2006년 $69.1 \%, 2008$ 년 $64.1 \%$ 였다. 안내서를 이용하거나 비디 오나 컴퓨터 등을 이용하여 상담을 한 경우도 있었다(Table 4).

\section{(3) 불임상담 장소}

불임상담을 '의사 진료실’에서 받은 경우가 가장 많았는데, 각 2006년 $75.3 \%, 2008$ 년 $61.2 \%$ 였다. '불임 전문상담실'에서 받은 경우가 두 번째 로 많았으며, 그외 간호사실, 강당, 병원 로비, 일반 접수실 등이 있었다. 특히 정신과 진료실에서 받았다는 경우는 2006년에는 한 명도 없었으 며, 2008년의 경우 20명(1.6\%) 있었다(Table 4).

\section{(4) 불임상담 시 심리검사}

불임상담시 심리검사를 하지 않았다는 경우가 가장 많았는데, 2006 년은 $95.9 \%, 2008$ 년은 $90.1 \%$ 이었다. 심리검사를 받은 경우는 22 명

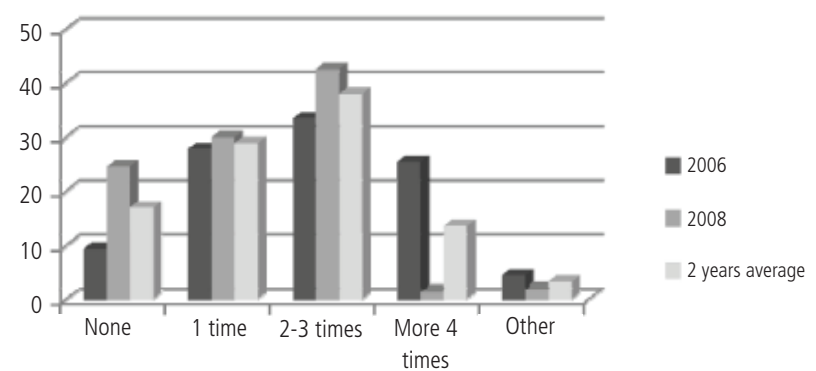

Fig. 3. Numbers of counseling before initiation of in vitro fertilizationembryo transfer treatment.

Table 2. Type of counselor of infertile couple

\begin{tabular}{|lccc|}
\hline Counselor & $\mathbf{2 0 0 6} \mathbf{~ y r}$ & $\mathbf{2 0 0 8} \mathbf{~ y r}$ & Mean \\
\hline Physician & $1009(85.5)$ & $879(67.7)$ & $944(76.6)$ \\
Nurse in charge & $111(9.4)$ & $202(15.6)$ & $157(12.5)$ \\
Psychiatrist, Psychologist & $17(1.4)$ & $26(2.0)$ & $22(1.7)$ \\
Administrative staff & $7(0.6)$ & $25(2.0)$ & $16(1.3)$ \\
Other & $37(3.1)$ & $164(12.7)$ & $101(7.9)$ \\
Total & $1181(100.0)$ & $1296(100.0)$ & $1239(100.0)$ \\
\hline
\end{tabular}

Values are presented as number (\%). 
Table 3. Cost for infertility counseling

\begin{tabular}{|lccc|}
\hline Cost & $\mathbf{2 0 0 6}$ yr & $\mathbf{2 0 0 8} \mathbf{~ y r}$ & Mean \\
\hline Do not pay & $659(59.8)$ & $765(61.3)$ & $712(60.6)$ \\
Less than 20,000 won & $225(20.1)$ & $183(14.6)$ & $204(17.4)$ \\
$30,000-50,000$ won & $81(7.2)$ & $63(5.0)$ & $72(6.1)$ \\
More than 10,000 won & $40(3.6)$ & $40(3.2)$ & $40(3.4)$ \\
Other & $116(10.3)$ & $199(15.9)$ & $158(13.1)$ \\
Total & $1121(100.0)$ & $1250(100.0)$ & $1185(100.0)$ \\
\hline
\end{tabular}

Values are presented as number (\%).

Table 4. The methods of infertility counseling

\begin{tabular}{|c|c|c|c|}
\hline & & $2006 \mathrm{yr}$ & $2008 \mathrm{yr}$ \\
\hline \multirow[t]{4}{*}{ Form } & Patient or couple alone & $1134(96.7)$ & $1060(84.0)$ \\
\hline & 2-5 persons & $21(1.8)$ & $26(2.0)$ \\
\hline & More than 5 persons & $7(0.6)$ & $6(0.5)$ \\
\hline & Other & $11(0.9)$ & $170(13.5)$ \\
\hline \multirow[t]{4}{*}{ Method } & Verbal counseling & $954(69.1)$ & $685(64.1)$ \\
\hline & Guide book & $338(24.4)$ & $180(16.9)$ \\
\hline & Video & $57(4.1)$ & $13(1.2)$ \\
\hline & Other & $33(2.4)$ & $190(17.8)$ \\
\hline \multirow[t]{5}{*}{ Place } & Office of physician & $885(75.3)$ & $754(61.2)$ \\
\hline & Infertility specialty counseling center & $237(20.2)$ & $244(19.8)$ \\
\hline & Nurse office & $39(3.3)$ & $64(5.2)$ \\
\hline & Psychiatric counseling center & $0(0.0)$ & $20(1.6)$ \\
\hline & Other & $14(1.2)$ & $150(12.2)$ \\
\hline \multirow[t]{3}{*}{ Psychological test } & Done & $22(1.9)$ & $31(2.5)$ \\
\hline & Not done & $1133(95.9)$ & $1105(90.1)$ \\
\hline & Unknown & $27(2.2)$ & $91(7.4)$ \\
\hline
\end{tabular}

Values are presented as number (\%).

(1.9\%, 2006년), 31명(2.5\%, 2008년)으로 매우 적었으며, 기타 심리 전 문가에게 상담받고 싶었으나 전문기관도 없고 정보가 없어서 받지 못하 였고, 혼자 힘들었다는 의견도 있었다(Table 4).

\section{5) 불임시술 중 스트레스를 받은 경우}

불임시술 중 가장 스트레스를 받은 경우는 '임신결과 발표 시'로 2006년 53.3\%, 2008년 64.1\%였다. 그외 난자채취 시, 난관조영술 시, 배아이식 시, 복강경검사 시 등의 순서로 스트레스를 많이 받은 것으로 나타났다. 기타 '유산되었을 때', '난자채취 후 난자의 개수가 적을 때', '매일 주사 맞는 것', 그리고 '불임시술 모든 과정이 다 스트레스였다'는 의견도 있었다(Fig. 4).

\section{6) 불임치료 시 가장 도움을 준 사람}

불임치료 시에는 가장 도움을 많이 준 사람으로 배우자가 가장 많았
는데, 각 1,213명 중 802명(66.1\%, 2006년), 2,226명 중 569명(25.6\%. 2008년)로 나타났다. 그외 친정식구가 두 번째로 많았으며, 친구, 담당 간호사, 불임전문의, 불임동호회 회원의 순서였다. '아무도 도와주는 사 람이 없었다'는 응답도 각 62 명 $(5.1 \%, 2006$ 년), 69 명(3.1\%, 2008년)이 있었다. 기타 불임기간이 길어지고 계속 임신이 실패하게 되면 남편도. 친정식구도, 친구의 위로를 받아도 전혀 도움이 안되었다는 의견도 있 었다(Fig. 5).

\section{7) 불임상담으로 인한 병원을 옮긴 적이 있는가 유무}

불임상담 또는 설명을 잘 해주지 않아 '병원을 옮긴 경우가 있는가' 에 대한 질문에 '없었다'는 경우가 가장 많았는데, 2006년은 1,167명 중 779명(66.8\%), 2008년은 1,259명 중 839명(66.7\%)이었다. "병원을 옮긴 경우가 있다'는 경우도 각 2006년의 경우 29.6\%, 2008년의 경우 $19.9 \%$ 나 되었다. 이는 불임 치료병원 선택 시 가장 중요한 요소는 임신 


\section{KOREAN JOURNAL OF OBSTETRICS \& GYNECOLOGY}

Ra Hyun Kim, et al. Infertility counseling in Korea



Fig. 4. The most stressful event during infertility treatment.

율이지만, 불임상담도 또 다른 요인이 될 수 있음을 나타내고 있다.

\section{고 찰}

최근 출산율이 저하되면서 정부주도의 불임부부 지원사업이 시행되 고 불임 환자들에 대한 관심이 증가되고 있다. 하지만 불임시술을 시행 하는 기관에 대한 정부차원의 물적 정도 관리는 시행되고 있는 반면에 아직 국내에서는 불임부부 상담에 대한 관심은 저조한 편으로 상담 기 준이나 권고안은 아직 만들어지지 않아 체계적인 상담이 이루어지지 않 고 있는 실정이다.

본 연구에서 외국의 경우와 비교하여 심리검사를 받지 않은 경우가 95.9\% (2006년), 90.1\% (2008년)로 매우 높게 나타났다. 심리 진단의 목적은 불임환자의 과거와 현재의 심리에 대해 정보를 모으는 것으로 이는 임상면담과 심리검사의 두 가지 방법이 사용된다. 임상면담은 개 인사(가족, 교육, 직업, 사회적 경력)와 심리상담을 하게 된 현재 사건 에 대한 지각과 정신상태와 일반적인 대인관계 방식을 파악해내는 것 인 반면, 심리검사는 환자에게 표준화된 방식으로 객관적 정보를 얻을 수 있다는 장점이 있다. 임상 면담은 정해진 시간 동안 불임환자에 대 한 정보를 쉽게 획득할 수 있는 방법이지만, 임상의가 면담자료를 확 인하거나 반박하기 위해서는 객관적인 2차 정보원을 필요로 하며, 이 런 경우 로-샤의 잉크얼룩검사(Rorschach inkblot test)나 다면적인성 검사(Minnesota multiphasic Inventory)와 같은 표준화된 심리검사가 유용하다.

본 연구의 결과를 보면, 심리검사를 받은 불임 환자는 각 1.9\% (2006 년), $2.5 \%$ (2008년)로 매우 적었는데, 이는 외국의 경우와 비교해 볼 때 현저하게 낮은 결과이며[4], 또한 본 연구에서는 구체적인 심리검사의 종류나 결과에 대한 조사를 하지 않아 이에 대하여는 추가 조사가 필 요할 것으로 생각된다. 2001년 유럽생식의학 및 발생학회(European Society of Human Reproduction and Embryology)와 1999년 미국생식 의학회(American Society for Reproductive Medicine)에 따르면[5] 불임 상담을 담당하는 사람은 해당 자격증을 취득하거나 자격을 인정받은 사

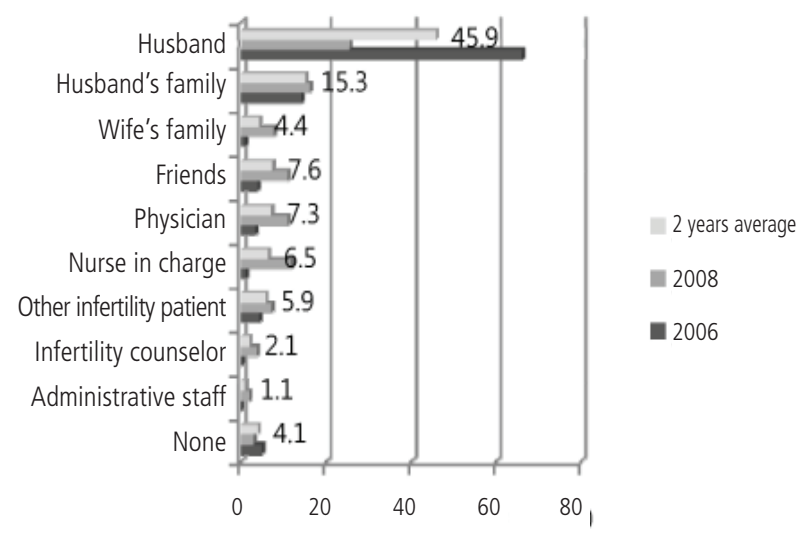

Fig. 5. The most helpful people during infertility treatment.

람, 또는 정신과전문의로 일정이상의 임상경험을 가지고 있어야 한다고 권유하고 있다. 본 조사에 따르면 국내에서는 불임상담을 대부분 산부 인과 전문의가 담당하고 있으나, 불임시술기관에 불임전담 간호사 근무 가 의무화되면서 간호사의 상담비중이 높아지고 있어, 해당 인력의 상 담기법교육 및 자격을 객관화 하려는 노력이 필요할 것으로 생각된다.

상담내용에 있어서도 정신과 전문의의 참여가 저조하였으며(2006 년: 0\%, 2008년: $1.6 \%$ ) 상담 시에 심리검사를 시행하지 않은 경우도 많은 것으로 나타났는데, Smeenk 등[6] 및 Boivin과 Takefman [7]의 연 구에 의하면 불임시술을 받는 여성에서 스트레스 정도가 심할 수록 낮 은 생물학적 반응 및 낮은 임신율을 나타낸다고 보고하였고, Domar와 Dreher [8] 및 Cousineau [9]는 많은 수의 불임부부들이 정신적인 스트 레스로 힘들어 하고 있으며, 스트레스 및 위기대처에 대한 상담으로 도 움을 받을 수 있고 임신결과에도 좋은 영향을 미친다고 하여 불임상담 시에 심리적인 특면에 대한 상담의 중요성을 강조하였다. 이에 국내에 서도 불임부부의 상담에 정신심리 전문가가 포함된 팀으로서의 접근이 필요할 것으로 생각된다.

또한, Boivin 등[4]에 의하면 불임상담을 받지 않으려는 환자들 중 대 다수가 배우자나 가족들을 통해서 위로를 받으려고 하며, 스트레스 정 도가 심할수록 불임상담을 외면하는 경향을 보여 구두를 통한 상담뿐 아니라 문서 또는 만화 등을 활용한 지식전달 및 자연스럽게 상담으로 이어질 수 있는 방법 등을 제시하였다. 국내에서도 추후 정신심리전문 가가 포함된 팀 접근방법과 쉬운 설명서 제작 및 불임부부들이 자유롭 게 상담을 받을 수 있는 환경 조성이 필요하다.

최근 불임치료의 주요한 관심 중의 하나는 불임상담에 관한 것이다. 그동안 불임상담은 일반 불임환자에게는 덜 중요하고 필요하지 않은 것 으로 생각되어 왔다. 불임인 사람들은 의학적으로는 물론이고 정서적으 로도 어렵고 힘든 상황에 처하게 되지만, 비용과 보험부담 등의 문제 때 문에 의학적 치료나 정서적 치료 중 하나를 선택하게 되고, 대부분의 경 우 보다 접근하기 쉬운 의학적 처치만 하게 된다. 불임에 대해 의학적, 정서적 처치를 통합해서 적용하기 위한 제안에는 1) 의료기관마다 총체 적 의료서비스의 일환으로 전문진을 구성하도록 하는 것, 2) 주 지정 병 원과 가까운 지역 병원의 협력시스템, 3) 지역사회의 지원자를 양성하여 


\title{
KOREAN JOURNAL OF OBSTETRICS \& GYNECOLOGY
}

\author{
KJOG Vol. 54, No. 10, 2011
}

준 전문가로 활용하는 것, 4) 컴퓨터를 이용한 채팅방을 만들어 활용하 는 것 등의 방법이 있는 것으로 권유되고 있다[10].

가장 중요한 것은 불임상담은 모든 불임 환자에게 쉽게 받을 수 있도

록 개방되어야 한다는 것이다. 이는 환자의 정신적 건강과 사회적인 건 강을 증진시키고 궁극적으로는 불임 치료에서 이탈되는 율을 최소화 시 키는 데 즉 임신을 포기하지 않는 데 도움이 될 수 있을 것으로 생각된 다.

또한, 향후 여러 가지 불임상담 기법이 우리나라 불임부부의 치료과 정에 미치는 영향과, 이러한 영향들이 임신율을 비롯한 치료결과에 어 떠한 도움이 될 것인가에 대한 연구가 필요할 것으로 생각된다.

\section{References}

1. Covington SN. The role of the mental health professional in reproductive medicine. Fertil Steril 1995;64:895-7.

2. Silman R. What is fertility counseling? In: Jennings $S$, editor. Infertility counselling. Oxford: Blackwell Science; 1995. p.205-13.

3. Hwang NM, Hwang JY, Kim JM. The evaluation of national supporting program for infertility and future policy directions. Seoul: Korea Institute for Health and Social Affairs; 2010. Re- port No. 2010-30-13.

4. Boivin J, Scanlan LC, Walker SM. Why are infertile patients not using psychosocial counselling? Hum Reprod 1999;14:1384-91.

5. Boivin J, Appleton TC, Baetens P, Baron J, Bitzer J, Corrigan E, et al. Guidelines for counselling in infertility: outline version. Hum Reprod 2001;16:1301-4.

6. Smeenk JM, Verhaak CM, Eugster A, van Minnen A, Zielhuis $G A$, Braat DD. The effect of anxiety and depression on the outcome of in-vitro fertilization. Hum Reprod 2001;16:1420-3.

7. Boivin J, Takefman JE. Stress level across stages of in vitro fertilization in subsequently pregnant and nonpregnant women. Fertil Steril 1995;64:802-10.

8. Domar AD, Dreher H. Healing mind, healthy woman: using the mind/body connection to manage stress and take control of your life. New York: Henry Holt; 1996.

9. Cousineau TM, Domar AD. Psychological impact of infertility. Best Pract Res Clin Obstet Gynaecol 2007;21:293-308.

10. Thorn P. Understanding infertility: psychological and social considerations from a counselling perspective. Int J Fertil Steril 2009;3:48-51. 


\section{KOREAN JOURNAL OF OBSTETRICS \& GYNECOLOGY}

Ra Hyun Kim, et al. Infertility counseling in Korea

\section{한국의 보조생식술을 시행 받은 불임환자들의 상담실태에 대한 조사}

${ }^{1}$ 한양대학교 의과대학 산부인과학교실, ${ }^{2}$ 한양대학교 의과대학 예방의학교실, ${ }^{3}$ 서울대학교 의과대학 산부인과학교실

김라현, 김영재, 호정규 ${ }^{1}$, 한동운, 최영민 ${ }^{3}$, 황정혜

목적

본 연구에서는 불임부부 지원사업을 받아 보조생식술을 시행 받은 불임환자들을 대상으로 불임상담 실태에 대하여 알아보고자 하였다.

연구방법

2006년과 2008년 각각 1년 동안 불임부부 지원사업의 시술비를 지원받은 불임환자 2006년 19,131예 중 7,931예와 2008년 13,240예 (총 21,171예)를 대상으로 우편설문조사를 실시하였다.

결과

불임시술 이전에 상담 받은 횟수는 2내지 3회 상담을 시행 받은 경우가 각각 409명(33.4\%, 2006년), 534명(42.4\%, 2008년)으로 가장 많 았으며, 불임부부에게 불임상담을 해준 상담자로 불임전문의에게 상담을 받았다고 한 경우가 2006년은 1,009명(85.5\%), 2008년은 879 명(67.7\%)으로 가장 많았다. 불임상담의 형태로는 진료실에서 불임환자나 부부 단독으로 구두상담 받은 경우가 가장 많았으며, 불임상담 시 심리검사를 하지 않았다는 경우가 대부분이었다. 불임시술 중 가장 스트레스를 받은 경우는 '임신결과 발표 시’로 나타났으며, 불임치 료 시에는 가장 도움을 많이 준 사람으로 배우자가 가장 많았다.

결론

불임시술 전 과정이 불임환자에게 스트레스를 주는 것으로 나타났다. 특히 임신 결과 발표 시에 가장 많은 스트레스를 받는다고 하였으며, 시술이전에 2-3회의 상담을 받았고, 상담 시 심리검사 등은 시행하지 않았다. 우리나라의 불임상담은 외국과는 달리 정신과 전문의나 정 신건강전문가에게 받지 않고 대부분 불임전문의에게 상담받았다고 하였는데, 국내에서도 불임부부의 상담에 정신심리 전문가가 포함된 팀으로서의 접근이 필요할 것으로 생각된다. 향후 불임상담과 임신율과의 상관 관계에 대한 추가 연구가 필요할 것으로 생각된다.

중심단어: 불임, 불임상담, 체외수정 및 배아이식술 